\title{
One-step electropolymerization of methylene blue films on highly flexible carbon fiber electrode as supercapacitors
}

\author{
Leandro Marques Samyn ${ }^{1}$, Rajendran Suresh Babu ${ }^{1 *}$, Mani Devendiran ${ }^{2}$ and Ana Lucia Ferreira de Barros ${ }^{1}$
}

\begin{abstract}
Energy crisis and environmental pollution have been one of the major global issues. In this regard, the search for new energy storage materials is cheap, flexible and high-performance supercapacitors electrode which has become intensive. Also, reducing the amount of organic dyes polluting in water is a great significance. Herein, one-step electropolymerization of methylene blue on carbon fiber and the resulting films were applied to the supercapacitor. The high performance is associated to the outstanding conductivity, electrochemical stability and superior mechanical flexibility of carbon fiber. A new flexible electrode for supercapacitors was successfully fabricated by demonstrating with a good electrochemical performance and a promising alternative to reduce the water pollution.
\end{abstract}

Keywords: Supercapacitors, Methylene blue, Organic dye, Carbon fiber fabrics, Electropolymerization

\section{Introduction}

Modifications are made in the surface of an electrode can could alter its mechanical and electrochemical properties. Various modification methods such as adsorption, bonding and deposition are used for this purpose [1]. Another method used for the modification of electrodes is the electropolymerization, which has some advantages like good uniformity in electrodes coating, which could not be obtained by others methods and the possibility of change in the properties of the coated polymers. The polymers obtained from electropolymerization may present specific properties were described earlier [2-4].

The various purposes of electrodes applications sometimes become necessary for the electrode material to possess with different properties. Carbon fiber fabrics (CFF) as materials are used as supercapacitors electrodes that have exceptional properties such as light weight, strength, flexibility, energy storage capacity and low cost,

\footnotetext{
*Correspondence: suresh.rajendran@aluno.cefet-rj.br

1 Laboratory of Experimental and Applied Physics, Centro Federal de Educação Tecnológica Celso Suckow da Fonseca (CEFET/RJ), Av.

Maracanã 229, Rio de Janeiro 20271-110, Brazil

Full list of author information is available at the end of the article
}

which are the desirable characteristics for smart and wearable technologies and nanodevices [5, 6]. However some properties of this fabric may be modified by giving this material to a whole new range of applications.

Recently, deposition of polyaniline doped with metalhexacyanoferrates nanoparticles were improved the electrical conductivity and specific capacitance of the electrode material turning to be applicable for the energy storage devices as supercapacitors and batteries $[5,6]$. The environmental impact caused by improper disposal of materials can made the use of organic dyes, which feature electroactivity properties being able to be artificial electron donors (acceptors) in enzyme reactions and to undergo electropolymerization, some are very interesting materials to be used for new coating materials applied to the electrodes [7-9]. Methylene blue is the phenothiazine derivative dyes which have an attracting attention since it presents catalyst material behaviour in the presence of biomolecules and different inorganic compounds $[10,11]$. One of the primary advantages of electropolymerization of methylene blue (MB) lies in the stability of the resulting polymer, which is synthesized from a low cost monomer in aqueous solution [2]. Obviously, the existence of reversible redox pair in $\mathrm{MB}$ may have the 
potential ability for storage of charge and they can be utilized as active electrode materials for pseudocapacitors. According to the above benefits, the component of dye molecules in the dye-containing effluents could be reutilized as electrochemical energy storage materials [1214]. Previously, the electrochemical polymerization of $\mathrm{MB}$ on platinum foil using $0.76 \mathrm{mM}$ of $\mathrm{MB}$ in electrolytes containing $0.05 \mathrm{M}$ sodium tetraborate and $0.5 \mathrm{M} \mathrm{KCl}$ with different $\mathrm{pHs}$ were observed [15]. Kertesz and Berkel using a $3 \mathrm{mM} \mathrm{MB}$ concentration in a buffer solution $(\mathrm{pH}$ 6.8) with a glassy carbon electrode reached $100 \mu \mathrm{A}$ of anodic current and investigated with electrospray mass spectroscopy [16]. Zhao et al. using $1.0 \mathrm{mM}$ of $\mathrm{MB}$ in a PBS electrolyte obtained an anodic peak current of 300 $\mu \mathrm{A}$ [3]. Liu et al. electropolymerized with a concentration of $2.0 \mathrm{mM}$ of $\mathrm{MB}$ in GC electrode in $0.2 \mathrm{M} \mathrm{Na}_{2} \mathrm{SO}_{4}(\mathrm{pH}$ 2.0) at sweep rate of $50 \mathrm{mVs}^{-1}$ [1]. Recently, using carbon cloths with graphitic outer layers and a gel electrolyte doped with $50 \mathrm{mM}$ of $\mathrm{MB}$ obtained $30 \mathrm{mAcm}^{-2}$ of areal current [14]. The MB pre-adsorbed on activated carbon obtained more than $60 \mathrm{~mA}$ in a $1.0 \mathrm{M} \mathrm{H}_{2} \mathrm{SO}_{4}$ [17].

Herein, we demonstrated the polymerization of $\mathrm{MB}$ in carbon fiber fabrics and used as electrodes for supercapacitor. Cyclic voltammetry was used to deposit the polymer films on the surface of the CFF electrode in $0.5 \mathrm{M}$ $\mathrm{Na}_{2} \mathrm{SO}_{4}$ solution ( $\mathrm{pH}$ 2.0) as electrolyte. The choose by the alkaline electrolyte solution was made since it has obtained a good results $[7,10]$ in the influence of the solution $\mathrm{pH}$ in the growth of the film and the anodic peak current. It is known that the electropolymerization of MB reaches higher growth rates in basic solutions $[2,7$, 10]. Despite the studies involving the effects of electropolymerization of $\mathrm{MB}(\mathrm{PMB})$, the effects in the preparation of carbon fiber electrodes which are used for the supercapacitor studies are not established. The main purpose of this article is to investigate the electrodeposition of $\mathrm{MB}$ on a highly flexible carbon fiber fabrics with different concentrations using $\left(\mathrm{Na}_{2} \mathrm{SO}_{4}\right)$ basic solution for eletropolymerization by cyclic voltammetry technique. The surface and morphological characterization was performed by FTIR and FESEM studies. The electrochemical characterization of the obtained polymer film was carried out in acidic $\left(0.5 \mathrm{M} \mathrm{H}_{2} \mathrm{SO}_{4}\right)$ medium by, $\mathrm{CV}, \mathrm{GCD}$ and EIS.

\section{Experimental}

\section{Chemicals}

Methylene blue (MB) was obtained from Sigma Aldrich ${ }^{\circledR}$. All other chemicals were purchased from AnalaR-grade and used as received without further treatment. Carbon fiber fabrics types RC200P with low resistance were purchased from Barracuda ${ }^{\mathrm{TM}}$, Brazil. Double distilled water was used for all experiments.

\section{Material characterization}

Fourier transform infrared spectroscopy (FTIR) was performed with the Agilent Cary $630^{\circledR}$ FTIR spectrometer (USA) in the range from 4000 to $400 \mathrm{~cm}^{-1}$ allowing to identify the presence of the polymer at the carbon fiber electrode surface. Field emission scanning electron microscope (FESEM) obtained with Thermo Scientific ${ }^{\text {TM }}$ Quattro (ThermoFisher Scientific, USA) was used for the electrode surface morphological analysis.

Cyclic voltammetry (CV), galvanostatic charge-discharge (GCD) and electrochemical impedance spectroscopy (EIS) measurements were performed using the multi-potentiostat (IVIUM Technologies). The electrochemical measurements were made using a three-electrode cell topology in a $0.5 \mathrm{M} \mathrm{H}_{2} \mathrm{SO}_{4}$ aqueous solution as the electrolyte at room temperature. The $\mathrm{PMB} / \mathrm{CFF}$ electrode, platinum sheet and $\mathrm{Ag} / \mathrm{AgCl}$ electrode were used as working, counter and reference electrodes, respectively. The analysis of the PMB/CFF electrode was performed using $\mathrm{CV}$ at different scan rates ranging from 2 to $100 \mathrm{mV} \mathrm{s}^{-1}$. The electrochemical impedance spectroscopy (EIS) was carried out under halfwave potential by sweeping the frequency between $100 \mathrm{MHz}$ and $100 \mathrm{kHz}$ at amplitude of $50 \mathrm{mV}$.

From the obtained curves it is possible to observe a double-layer capacitive behavior from the carbon fiber and a pseudocapacitive contribution from $M B$ redox reactions. The capacitance value may be obtained through the integral of the graphic area applied in the below equation. The integral of the discharge area is necessary to determine the energy density since the Faradaic reactions make the charge/discharge curves non-symmetric [18-20]:

$$
C=\frac{2 i \int V d t}{V^{2} \mid \frac{V_{2}}{V_{1}}}
$$

where $C$ is the capacitance of the electrode $\left(\mathrm{F} \mathrm{g}^{-1}\right), \mathrm{i}$ is the current (A), $\int V d t$ is the integral current area of the discharge curve and $V$ is the potential with the initial and final value of $V_{1}$ and $V_{2}$, respectively. To obtain the specific current, it is necessary to divide the capacitance by the mass (g) of electroactive material deposited in the electrode surface.

\section{Electrodes fabrication}

Carbon fiber fabrics of $1.0 \mathrm{~cm} \times 1.0 \mathrm{~cm}$ were used as substrate material for the electrodes [21]. No specific preparation was necessary for preserving the CFF material characteristics (mechanical strength, flexibility, high conductivity and lightness). The deposition process of MB into the CFF electrodes surface was performed by 
cyclic voltammetry in the potential range between -1.0 and $1.5 \mathrm{~V}$ during 30 continuous cycles at a scan rate of $50 \mathrm{mV} \mathrm{s}^{-1}$ using aqueous solution containing $0.2 \mathrm{M}$ of $\mathrm{Na}_{2} \mathrm{SO}_{4}$ ( $\mathrm{pH}$ 2.0) with different concentrations of $\mathrm{MB}$ $(0.1,0.2,0.4,1.0 \mathrm{mM})$. The electrodes were dried at ambient temperature and washed with distilled water to remove the non-polymerized materials from the electrode surface and dried in air. The weight of the active material coated on the CFF electrode surface was optimized at $\sim 1.0 \mathrm{mg} \mathrm{cm}^{-2}$.

\section{Results and discussion}

\section{Electrochemical polymerization mechanism of $\mathrm{MB}$}

Polymerization of MB at carbon fiber electrode surface was performed by cyclic voltammetry $(\mathrm{CV})$ technique in the range between -1.0 to $1.5 \mathrm{~V}$ during 30 continuous cycles at a scan rate of $50 \mathrm{mV} \mathrm{s}^{-1}$. Figure $1 \mathrm{a}-\mathrm{d}$ shows the polymerization curves for $0.1,0.2,0.4$ and $1.0 \mathrm{mM} \mathrm{MB}$ concentration electrode at a scan rate of $50 \mathrm{mV} \mathrm{s}^{-1}$. From the obtained peaks it is possible to see the reversibility of the process and that the repetitive cycling leads to the formation of the polymer film. During the scanning of the positive potential, the polymerization reaction starts with adsorption of the monomer on the CFF electrode and the first anodic peak due to the MB monomer redox behavior at $0.41 \mathrm{~V}$ versus $\mathrm{Ag} / \mathrm{AgCl}$, and the irreversible second anodic peak corresponding to cation-radical species at more positive potentials at $0.72 \mathrm{~V}$. It might be before formation of the radical cation species, one of the substituents of the tertiary amino group is oxidized in a mechanism involving hydroperoxide. These reactive anions can attack one of the methyl groups of the tertiary amino group bound to the aromatic ring $[7,22,23]$. The redox mechanism of $\mathrm{MB}$ and polymerization path is suggested in Scheme 1.

\section{FTIR spectroscopy}

The FTIR spectra for the poly(methylene blue) in carbon fiber fabrics (PMB/CFF) electrodes with different molar ratios are presented in Fig. 2 for a convenient comparison and allowing the identification of the functional groups present in the polymer film. The infrared vibration bands
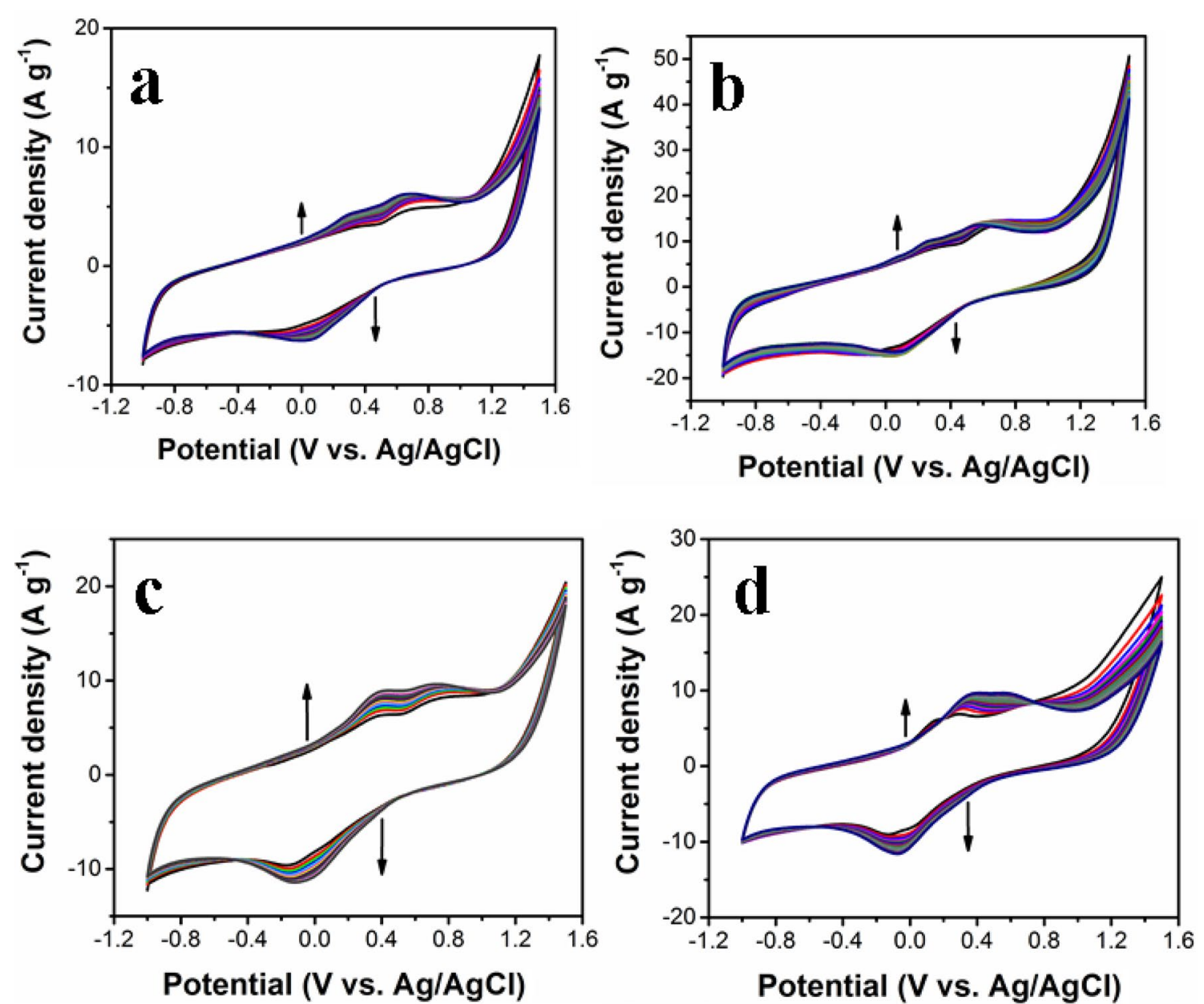

Fig. 1 CV curves of MB electropolymerization (50 cycles) for a $0.1 \mathrm{mM}, \mathbf{b} 0.2 \mathrm{mM}, \mathbf{c} 0.4 \mathrm{mM}$ and d $1.0 \mathrm{mM}$ MB concentration 
<smiles>CN(C)c1ccc2c(c1)Sc1cc(N(C)C)ccc1N2</smiles>

Scheme 1 Suggested growing mechanism of poly(methylene blue)

for the monomer $(\mathrm{MB})$ and the polymer at the carbon fiber showed the spectra according to previous studies [22]. The $\mathrm{MB}$ monomer showed a $\mathrm{C}=\mathrm{C}$ group in the aromatic ring at $1588 \mathrm{~cm}^{-1}$. The peak at $1310 \mathrm{~cm}^{-1}$ belong to the vibrations of $\mathrm{C}-\mathrm{N}$ bond of aromatic tertiary amine group and a peak near from $\sim 826 \mathrm{~cm}^{-1}$ associated to the bending vibrations of $\mathrm{N}-\mathrm{H}$ group of reduced $\mathrm{MB}$ monomer [12]. The out-of plane $\mathrm{C}-\mathrm{H}$ bending vibrations can also be observed at approximately $680 \mathrm{~cm}^{-1}[1,22]$. The various concentrations of PMB electrodes showed a peak at around 1666 and $1576 \mathrm{~cm}^{-1}$ belongs to the $\mathrm{C}=\mathrm{N}$ and phenyl ring $(\mathrm{C}=\mathrm{C})$ stretching vibrations, respectively. The polymerized electrodes showed the absence

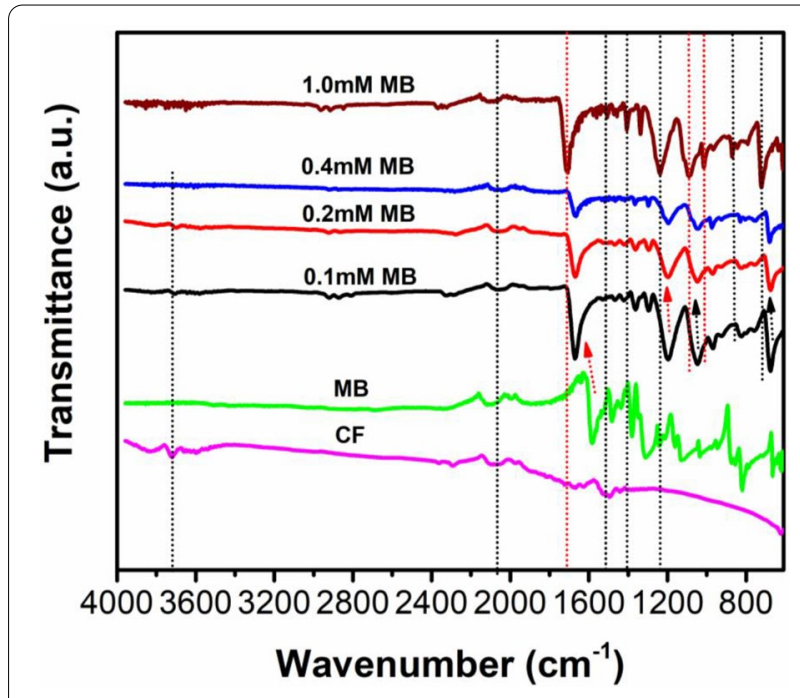

Fig. 2 FTIR spectra of CF bare electrode, MB monomer and MB coated electrodes for $0.1 \mathrm{mM}, 0.2 \mathrm{mM}, 0.4 \mathrm{mM}$ and $1.0 \mathrm{mM}$ concentrations of $\mathrm{N}-\mathrm{H}$ wagging peak at $820 \mathrm{~cm}^{-1}$ that due to the oxidation of MB. The aromatic tertiary amine $(\mathrm{C}-\mathrm{N})$ group also remains in the spectra confirms the polymer film coated on the CFF surface.

\section{FESEM analysis}

The surface characterizations of the PMB/CFF fabricated electrodes were performed by FESEM analysis. Figure $3 \mathrm{a}-\mathrm{d}$ shows the FESEM of various PMB/CFF electrodes fabricated with $0.1,0.2,0.4$ and $1.0 \mathrm{mM}$ concentrations of $\mathrm{MB}$, respectively. It can be seen that, the film has coated from the MB polymer into the unidirectional carbon fiber surface. Also, the good adhesion of the thin $\mathrm{MB}$ polymer was grown in CFF surface for higher concentrations.

Figure $4 \mathrm{a}-\mathrm{d}$ shows the EDS spectra to confirm the presence of $\mathrm{C}, \mathrm{N}$ and $\mathrm{S}$ in the CFF electrode surfaces. The elemental compositions were presented in Table 1 . Nevertheless, peaks from the electrolyte $(\mathrm{Na}, \mathrm{S}$ and $\mathrm{O})$ were inevitably due to the formation thin coating. The EDS of PMB electrodes were confirmed that the carbon is the predominant component in the electrodes with some small peaks of nitrogen and sulphur from the formation of MB coating.

\section{Effect of scan rate}

The electrochemical performance of the PMB electrodes with different concentrations was investigated by cyclic voltammetry at different scan rates ranging from 2 to $100 \mathrm{mVs}^{-1}$ in $0.5 \mathrm{M} \mathrm{H}_{2} \mathrm{SO}_{4}$ electrolyte (Fig. 5a-d). From the $\mathrm{CV}$ curves, it can be observed that, the combination between EDLC and pseudocapacitive effects in the charge storage. The EDLC behavior is typical from the porous carbon fiber can be utilized as electrode substrate 

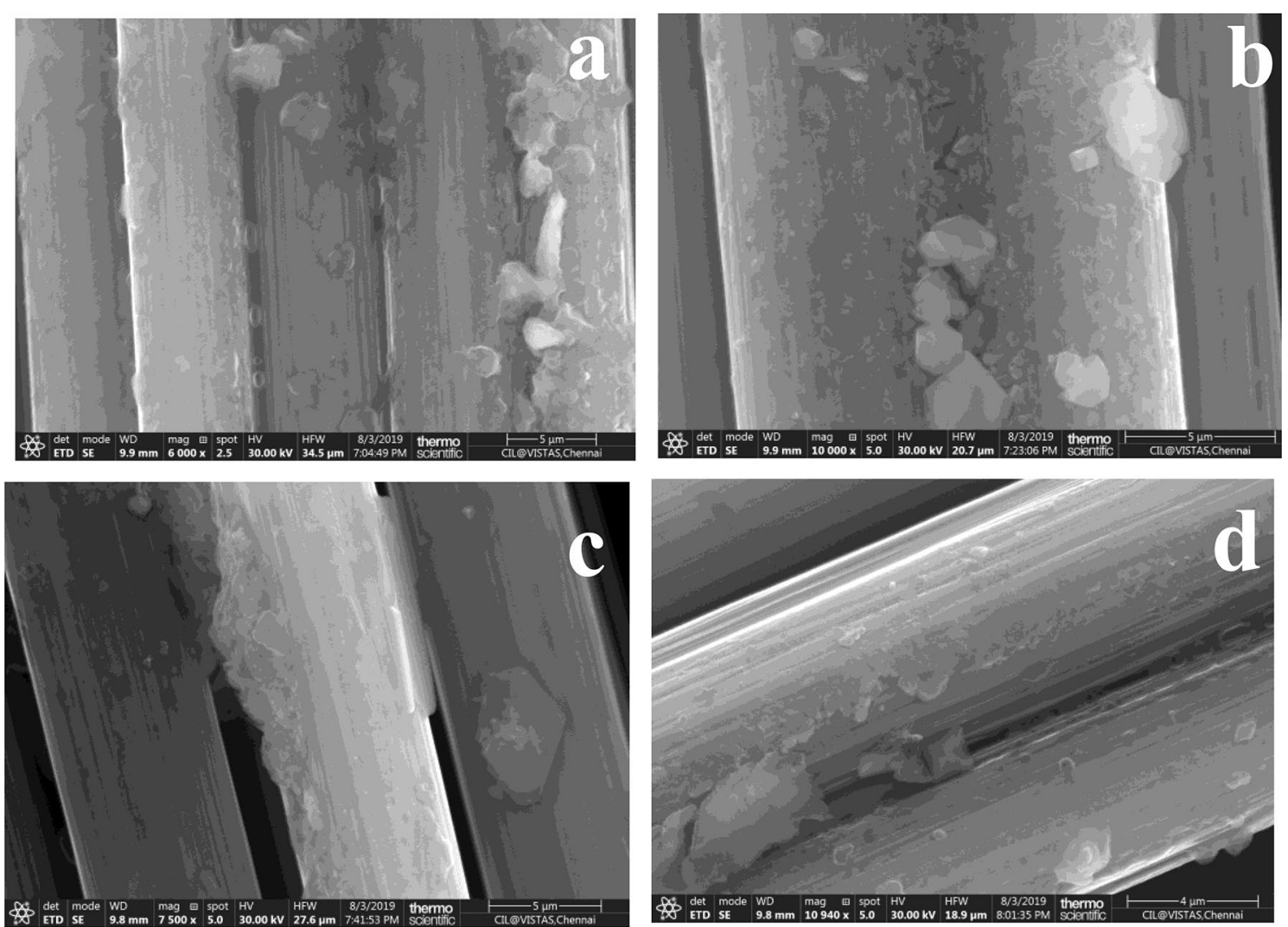

Fig. 3 FESEM images of PMB film with coated CFF using a $0.1 \mathrm{mM} \mathrm{MB}$, b $0.2 \mathrm{mM} \mathrm{MB}$ c $0.4 \mathrm{mM} \mathrm{MB}$ and d $1.0 \mathrm{mM}$ MB

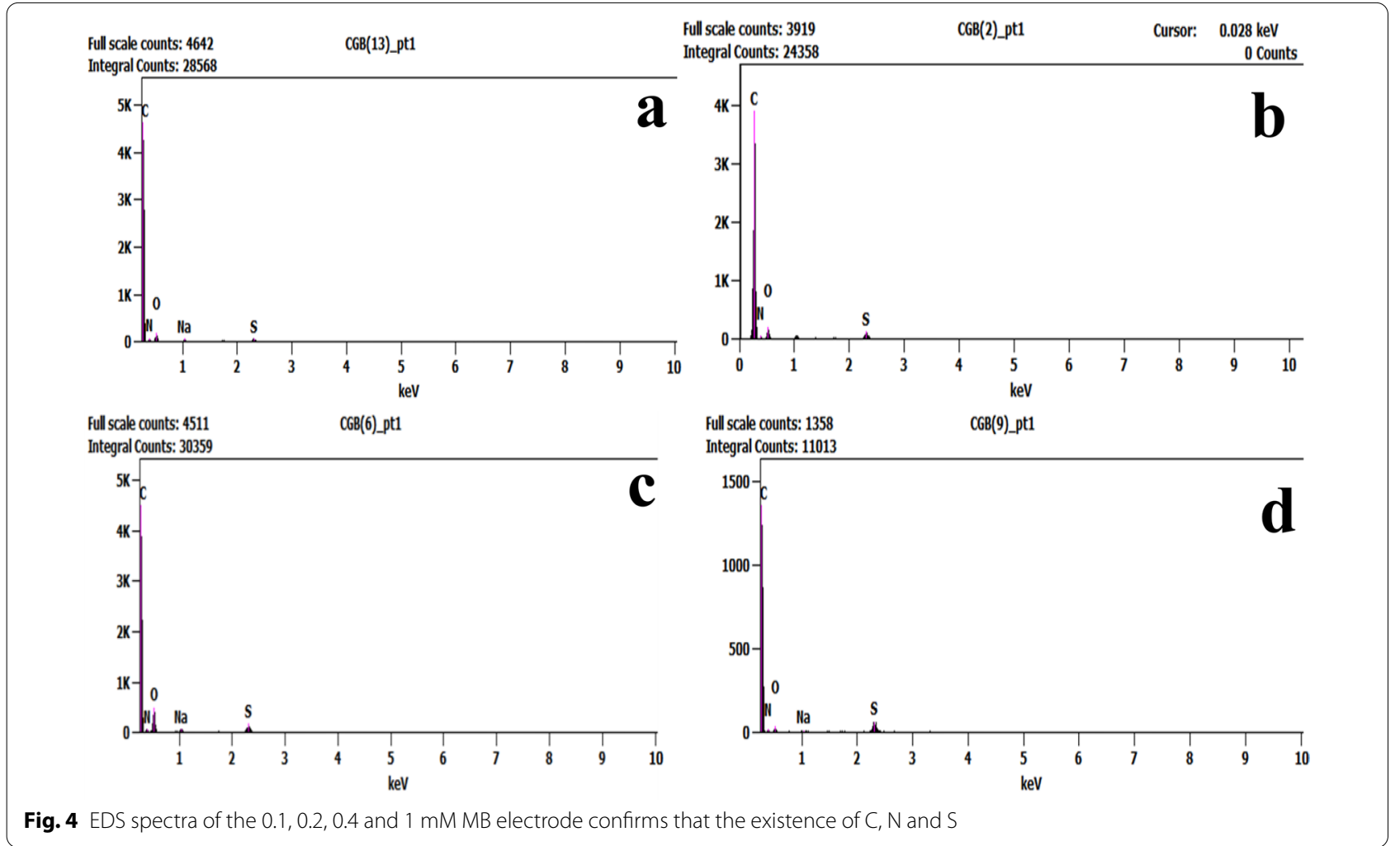


Table 1 Elemental composition for the electrodes with different MB concentrations

\begin{tabular}{llllll}
\hline Material (mM) & $\boldsymbol{C}(\mathbf{w t} \%)$ & $\boldsymbol{N}(\mathbf{w t} \%)$ & $\boldsymbol{O}(\mathbf{w t} \%)$ & $\mathbf{N a}(\mathbf{w t} \%)$ & $\boldsymbol{S}(\mathbf{w t} \%)$ \\
\hline 0.1 & 46.87 & 19.64 & 31.84 & 0.58 & 1.08 \\
0.2 & 54.95 & 21.81 & 21.44 & 0.52 & 1.28 \\
0.4 & 53.82 & 20.80 & 23.68 & 0.33 & 1.38 \\
1.0 & 68.31 & 18.43 & 11.04 & 0.15 & 2.07 \\
\hline
\end{tabular}

and current collector and it was expected to be an efficient electrode for polymerization. A typical behavior from pseudocapacitive materials was also identified by showing redox peaks where the current density increases with the MB concentration as shown in Fig. 5a-d. Typical oxidation and reduction peaks from the polymerization of $\mathrm{MB}$ at the electrode surface were exhibited after performed with a scan rate. The voltammogram for $0.1 \mathrm{mM} \mathrm{MB}$ were showed two small oxidation peaks, one near from $+450 \mathrm{mV}$ and another one close to $+660 \mathrm{mV}$ (versus $\mathrm{Ag} / \mathrm{AgCl}$ ). One big reduction peak can be seen near from $+120 \mathrm{mV}$ (versus $\mathrm{Ag} / \mathrm{AgCl}$ ) probably may be derived from the merge of two reduction peaks. It can also be observed that a small change in the peaks positions due to the increase of the scan rate.

\section{Galvanostatic charge-discharge}

The galvanostatic charge and discharge behavior of PMB/ CFF fabricated electrodes were examined at various current densities ranging from 0.3 to $5 \mathrm{~A} \mathrm{~g}^{-1}$ in the potential range from 0 to $0.6 \mathrm{~V}$ as shown in Fig. $6 \mathrm{a}-\mathrm{d}$. The results showed the capability of the electrode material to be applied in energy storage devices as supercapacitors. From the curves, it is possible to observe that the best behavior was obtained with $0.3 \mathrm{~A} \mathrm{~g}^{-1}$ and the discharge
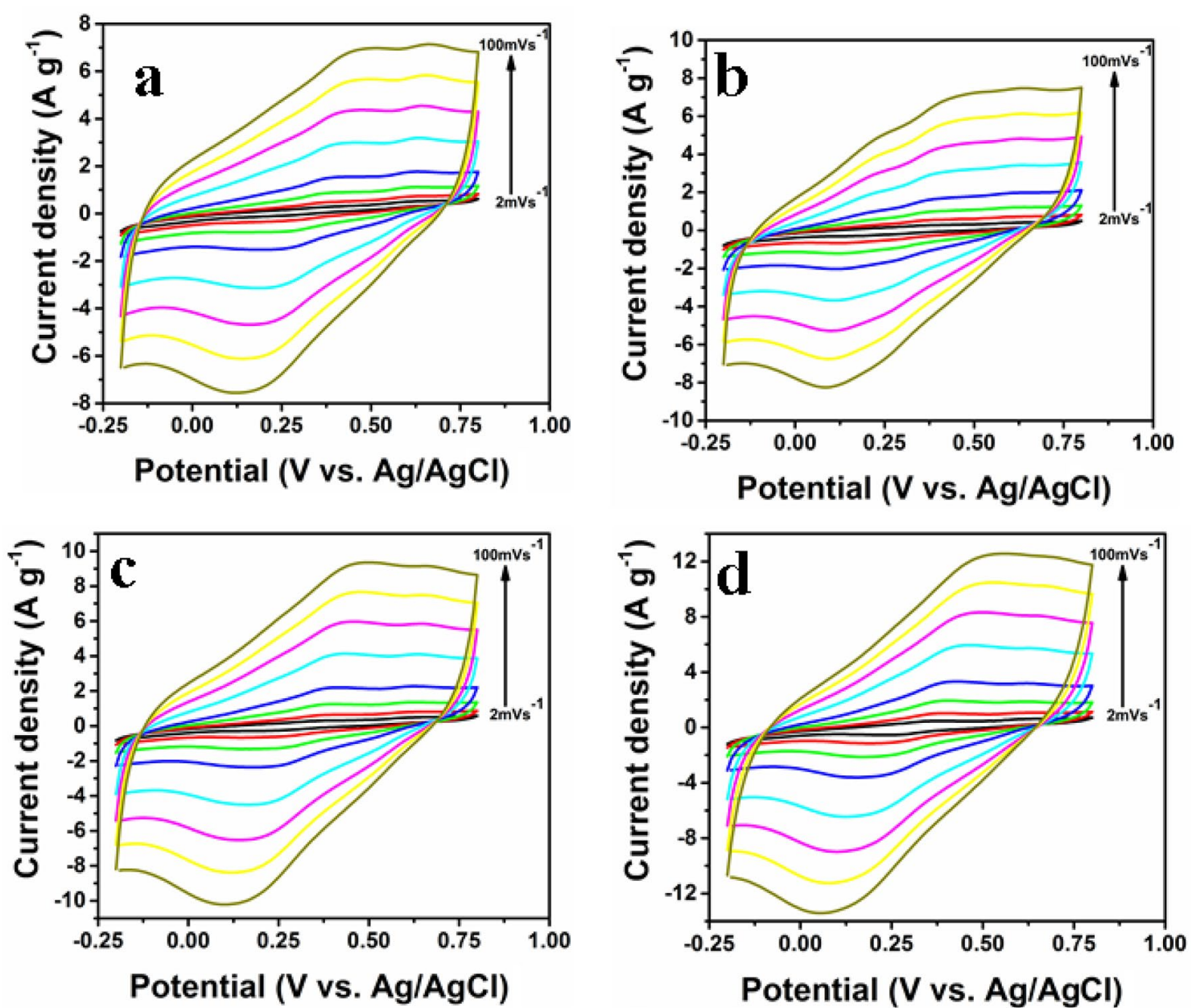

Fig. $5 \mathrm{CV}$ curves of $\mathrm{MB}$ electrodes at different scan rates in the potential range of -0.20 to $0.80 \mathrm{~V}(\mathrm{vs}$. Ag/ $\mathrm{AgCl})$ a $0.1 \mathrm{mM} \mathrm{MB}, \mathbf{b} 0.2 \mathrm{mM} \mathrm{MB}, \mathbf{c}$ $0.4 \mathrm{mM} \mathrm{MB}$ and $\mathbf{d} 1.0 \mathrm{mM} \mathrm{MB}$ 

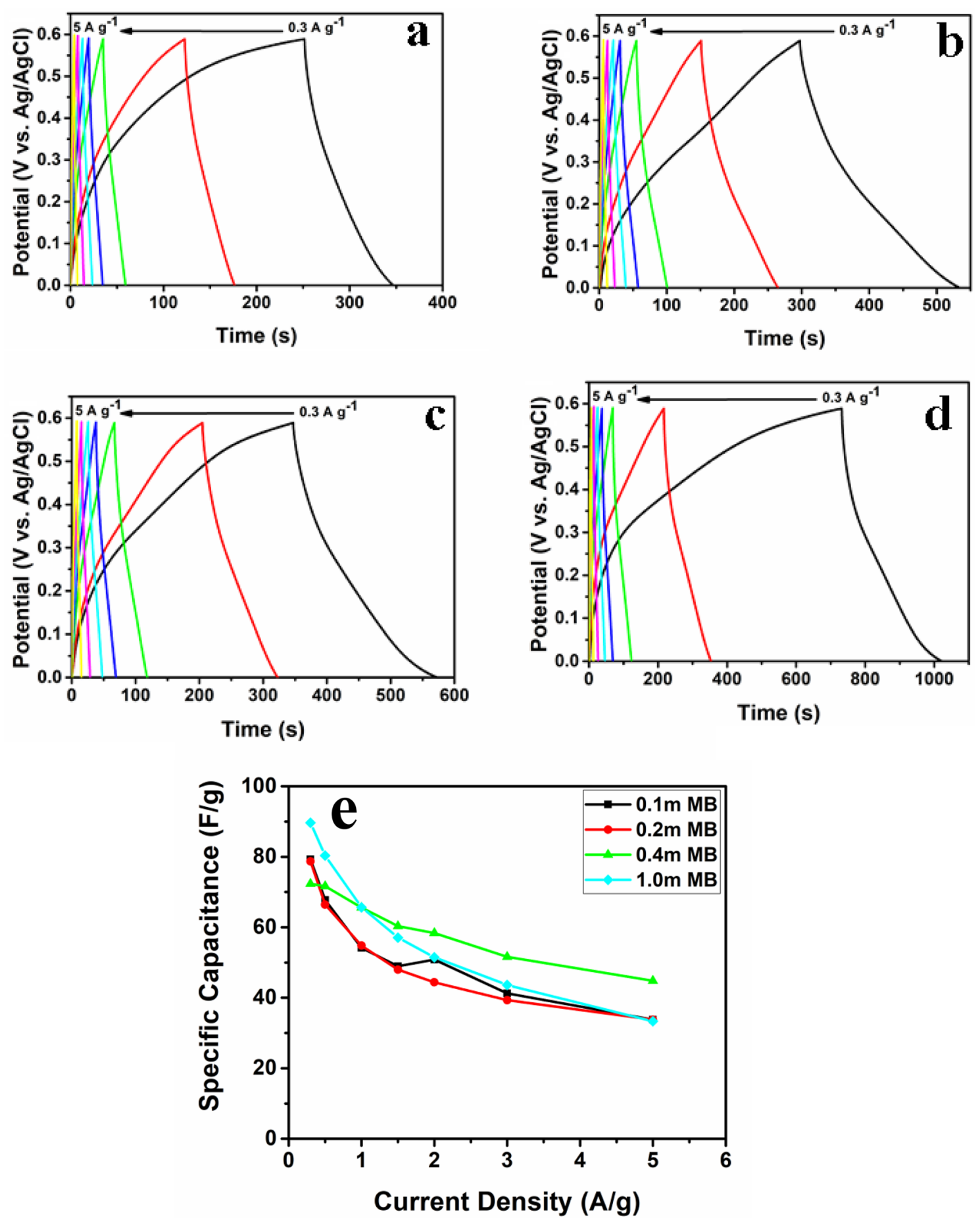

Fig. 6 Charge/discharge curves at different current densities of $\mathrm{MB}$ carbon fiber fabrics electrodes within an operating potential of $0 \sim 0.60 \mathrm{~V}$ (vs. $\mathrm{Ag} / \mathrm{AgCl}$ ) at different current densities 0.3 to $5 \mathrm{~A} \mathrm{~g}^{-1}$ a $0.1 \mathrm{mM} \mathrm{MB}, \mathbf{b} 0.2 \mathrm{mM} \mathrm{MB}, \mathbf{c} 0.4 \mathrm{mM} \mathrm{MB}, \mathbf{d} 1.0 \mathrm{mM} \mathrm{MB}$ and e specific capacitance comparison at different current densities

time increases with the MB concentration. An almost negligible IR drop in the discharge curve was observed for all current densities. This IR drop is associated to the internal resistance and ionic conductivity [11]. Despite the predominance of the EDLC energy storage process the inherent to the porosity of the electrode material and the pseudocapacitive behavior of the PMB. The coated film can be identified for higher concentrations 
of $\mathrm{MB}$ giving a hybrid behavior to the coated electrodes and improving its total capacitance. The electrical double layer capacitance on the carbon fiber electrode surface is associated to the charge accumulation at the electrode/ electrolyte solution boundary whereas the pseudocapacitance is promoted by the reduction/oxidation reactions of MB. From the Eq. 1, it is possible to determine the gravimetric specific capacitance using the discharge interval from the GCD profiles and the respective results are shown in the Fig. 6e. The $1.0 \mathrm{mM}$ electrode presented the highest specific capacitance of $89.67 \mathrm{~F} \mathrm{~g}^{-1}$ at a current density of $0.3 \mathrm{~A} \mathrm{~g}^{-1}$ It is important to note that the $0.4 \mathrm{mM}$ electrode has showed a good specific capacitance retention value with the increase in the current density (from 1 to $5 \mathrm{~A} \mathrm{~g}^{-1}$ ) which may be explained by stability of the polymer film at the electrode surface with the increase in the current density. During the experiments, it can be observed that the $1.0 \mathrm{mM}$ electrode has presented the leakage of the monomer to the electrolyte solution when the current density was more than $2 \mathrm{~A} \mathrm{~g}^{-1}$.

\section{Stability}

The long-term cyclic stability and reversibility results can provide important information for the as-prepared electrode. The cyclic performance of $1 \mathrm{mM} \mathrm{MB}$ was further examined by galvanostatic charge-discharge tests for 1000 cycles in the voltage range of 0.0 to $0.6 \mathrm{~V}$ with 0.3 A/g in three electrode system. From the Fig. 7, it can be seen a retention from approximately $95.5 \%$ in the available capacity over 1000 cycles. This implies an excellent long-term cycling capability offered by the electrode.

\section{EIS}

By the previous data, the electrodes have presented with two different storage mechanisms and ion transport phenomena that can be analyzed from EIS. Nyquist plot can be utilized by the frequency response of the electrode/ electrolyte system and can give information about electrochemical processes occurring in both parts. Generally, Nyquist plots can be represented by plotting with impedance real component ( $\left.Z^{\prime}\right)$ versus impedance imaginary component (Z"). Fitting data were obtained from the experimental results an equivalent electrical circuit can be found. Figure $8 \mathrm{a}-\mathrm{d}$ shows the fitted Nyquist plots of $0.1 \mathrm{mM}, 0.2 \mathrm{mM}, 0.4 \mathrm{mM}$ and $1.0 \mathrm{mM} \mathrm{PMB} / \mathrm{CFF}$ electrodes. The interception of the plotted data with the real axis is usually associated to the resistance of the electrolyte. But, from the obtained results it is possible to observe that the resistance $R_{\mathrm{S}}$ is probably not only the resistivity to inherent from the electrolyte. Since it varies from electrode to electrode using the same solution as electrolyte, it is more suitable that this resistance is characteristic of the resistivity of the material that composes

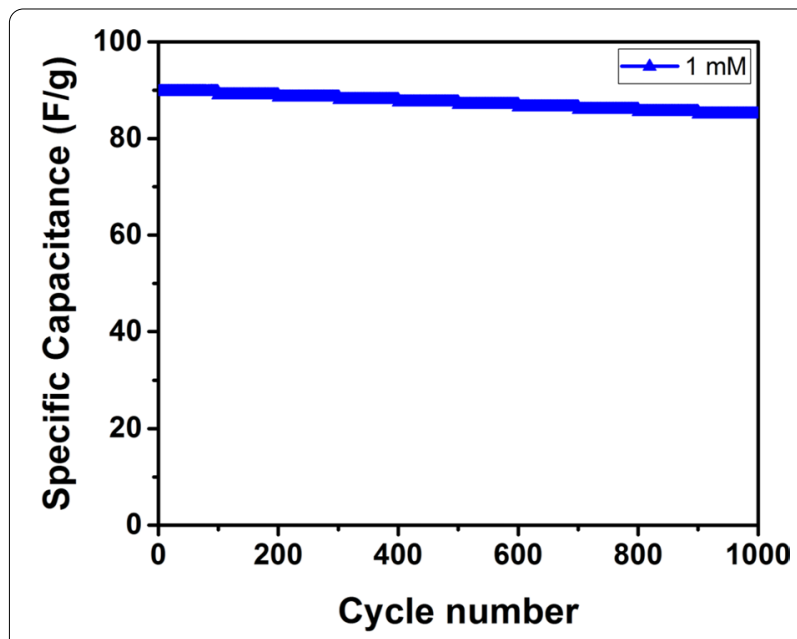

Fig. 7 Cyclic stability of 1. $0 \mathrm{mM} \mathrm{MB}$ electrode from charge/discharge studies at current density of $0.3 \mathrm{~A} / \mathrm{g}$

the electrode associated with the resistivity of the electrolyte. The transfer of electron resistance increases with increasing $\mathrm{MB}$ concentration from $0.1 \mathrm{mM}$ to $0.4 \mathrm{mM}$ indicating a growth in polymeric coating thickness and consequent reduction in electrode surface conductivity. At a concentration of $1.0 \mathrm{mM}$ this resistance drops considerably, possibly due to the loss of unpolymerized monomer adsorbed from the electrode surface to the electrolyte, making the charge transfer resistance $\left(R_{\mathrm{ct}}\right)$ of this electrode close to the resistance of the lowest $\mathrm{MB}$ concentrations. This may be explained by the loss of polymer film thickness due to the low polymerization of the monomer at $1.0 \mathrm{mM}$ concentration, which would also justify the reduction in specific capacitance compared to the $0.4 \mathrm{mM}$ concentration. The equivalent circuit values are summarized in Table 2 . The two constant phase elements of the equivalent circuit are associated to the capacitive characteristic of the porous electrode and the formation of the double layer on the electrode surface by the coating. The increase in constant phase element $(\mathrm{CPE})$ values, with the higher value at $0.4 \mathrm{mM}$ concentration, justifies the higher specific capacitance exhibited by this electrode. The frequency factor $(N)$, which defines the proximity of the CPE element with a resistor $(N=0)$ or an ideal capacitor $(N=1)$, showed the moderate values for the two constant phase elements indicated in the equivalent circuit.

\section{Conclusions}

Flexible PMB films on CFF were successfully fabricated by simple one-step electropolymerization using cyclic voltammetry method. The PMB/CFF exhibited a high specific capacitance of $89.67 \mathrm{~F} \mathrm{~g}^{-1}$ at a current density 

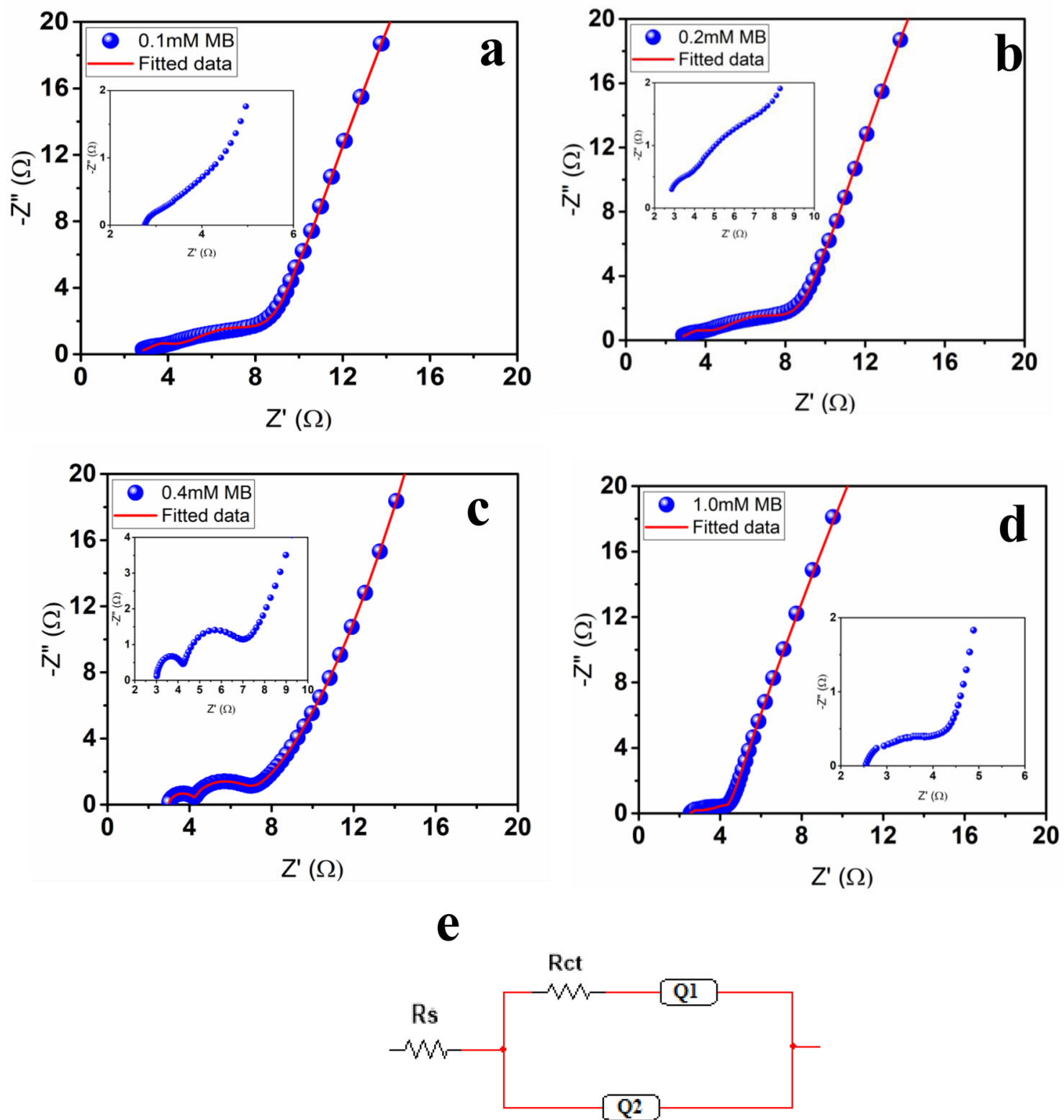

Fig. 8 Nyquist plots of the coated electrodes a $0.1 \mathrm{mM} \mathrm{MB}, \mathbf{b} 0.2 \mathrm{mM} \mathrm{MB}, \mathbf{c} 0.4 \mathrm{mM} \mathrm{MB}, \mathbf{d} 1.0 \mathrm{mM} \mathrm{MB}$ and e equivalent circuit obtained by the frequency response

Table 2 Fitting data of equivalent circuit elements obtained by the frequency response

\begin{tabular}{|c|c|c|c|c|c|c|}
\hline Electrode (mM) & $R_{\mathrm{s}}(\Omega)$ & $R_{\mathrm{ct}}(\Omega)$ & $Q_{1} \times 10^{-3}(\mathrm{~F})$ & $N_{1}$ & $Q_{2} \times 10^{-6}(\mathrm{~F})$ & $N_{2}$ \\
\hline 0.1 & 2.94 & 1.27 & 17.70 & 0.77 & 497.9 & 0.90 \\
\hline 0.2 & 2.80 & 2.45 & 28.22 & 0.78 & 578 & 0.70 \\
\hline 0.4 & 2.86 & 5.03 & 49.13 & 0.78 & 1032 & 0.72 \\
\hline 1 & 2.55 & 1.67 & 53.34 & 0.81 & 797.2 & 0.70 \\
\hline
\end{tabular}


of $0.3 \mathrm{~A} \mathrm{~g}^{-1}$ in a three-electrode system establishing that the MB film can be directly used for supercapacitors. Moreover, the high quality of the MB film (steadiness and robustness) and the good electrochemical performance make the MB suitable for being used in the fabrication of carbon fiber fabrics basis electrodes applied to pseudocapacitors given to increase its capacitance values. Utilize the variety of dyes from the wastewater containing redox properties can also possible to make efficient energy storage materials.

\section{Abbreviations}

MB: Methylene blue; PMB: Poly methylene blue; CFF: Carbon fiber fabrics; FTIR: Fourier transform infrared spectroscopy; FESEM: Field emission scanning electron microscope; CV: Cyclic voltammetry; GCD: Galvanostatic chargedischarge; EIS: Electrochemical impedance spectroscopy; Z': Impedance real component; Z": Impedance imaginary component.

\section{Acknowledgments}

We would like to thank the Brazilian funding agencies CAPES (BEX 5383/153), CNPq (301868/2017-4 and 407938/2018-4), FINEP (0647/18) and FAPERJ (E-241202/18 and E-245307/19). Dr. R. S. Babu wishes to acknowledge CAPES for the financial assistance in the form of PNPD Fellowship.

\section{Authors' contributions}

LMS: Fabrication of electrodes, investigation of electrodes, instumnets handing and analyzing the data, manuscript writing. RSB: Conceptualization and manuscript reviewing and editing. MD: FTIR and FESEM analysis. ALFB: Under her supervision and revised the manuscript (Langauge editing). All authors read and approved the final manuscript

\section{Funding}

FINEP (0647/18)

FAPERJ (E-241202/18 and E-245307/19).

CAPES (BEX 5383/15-3).

CNPq (301,868/2017-4 and 407,938/2018-4).

\section{Availability of data materials}

All data produced and analyzed in this study are included in this article.

\section{Competing interest}

The authors declare no conflicts of interest.

\section{Author details}

${ }^{1}$ Laboratory of Experimental and Applied Physics, Centro Federal de Educação Tecnológica Celso Suckow da Fonseca (CEFET/RJ), Av. Maracanã 229, Rio de Janeiro 20271-110, Brazil. ${ }^{2}$ Department of Analytical Chemistry, School of Chemical Sciences, University of Madras, Guindy Campus, Chennai 600 025, Tamil Nadu, India.

Received: 21 October 2020 Accepted: 9 February 2021

Published online: 22 February 2021

\section{References}

1. Liu B, Cang H, Cui L, Zhang H (2017) Electrochemical polymerization of methylene blue on glassy carbon electrode. Int J Electrochem Sci 12:9907-9913

2. Kaplan IH, Dağcı K, Alanyalıoğlu M (2010) Nucleation and growth mechanism of electropolymerization of methylene blue: The effect of preparation potential on poly (methylene blue) structure. Electroanalysis 22:2694-2701

3. Zhao RJ, Jiang Q, Sun W, Jiao K (2009) Electropolymerization of methylene blue on carbon ionic liquid electrode and its electrocatalysis to 3, 4-dihydroxybenzoic acid. J Chin Chem Soc 56:158-163
4. Hudak NS, Schlichting AD, Eisenbeiser K (2017) Structural supercapacitors with enhanced performance using carbon nanotubes and polyaniline. J Electrochem Soc 164:A691-A700

5. Babu RS, de Barros ALF, Maier MA, Sampaio DM, Balamurugan J, Lee JH (2018) Novel polyaniline/manganese hexacyanoferrate nanoparticles on carbon fiber as binder-free electrode for flexible supercapacitors. Compos Part B Eng 143:141-147

6. Maier MA, Babu RS, Sampaio DM, de Barros ALF (2017) Binder-free polyaniline interconnected metal hexacyanoferrates nanocomposites (Metal $=\mathrm{Ni}_{\text {, }}$ Co) on carbon fibers for flexible supercapacitors. J Mater Sci Mater Electron 28:17405-17413

7. Karyakin AA, Strakhova AK, Karyakina EE, Varfolomeyev SD, Yatsimirsky AK (1993) The electrochemical polymerization of methylene blue and bioelectrochemical activity of the resulting film. Synth Met 60:289-292

8. Li B, Li Z, Zhang L, Liu Z, Xiong D, Li D (2017) Facile synthesis of polyaniline nanofibers/porous carbon microspheres composite for high performance supercapacitors. J Taiwan Inst Chem E 81:465-471

9. Wu W, Niu D, Zhu J, Yang L, Shao Y, Fang Y, Cui Y (2018) Fluorescent modified graphene oxide/polyaniline nanowhiskers composites as smart electrode material for supercapacitors. J Taiwan Inst Chem E 82:117-128

10. Karyakin AA, Strakhova AK, Karyakina EE, Varfolomeyev SD, Yatsimirsky AK (1993) Bioelectrochem Bioenergetics 32:35-43

11. Braun WA, Horn BC, Hoehne L, Stülp S, Rosa MB, Hilgemann M (2017) Poly (methylene blue)-modified electrode for indirect electrochemical sensing of $\mathrm{OH}$ radicals and radical scavengers. Anais da Academia Brasileira de Ciências 89:1381-1389

12. Yu D, Wang H, Yang J, Niu Z, Lu H, Yang Y, Guo L (2017) Dye wastewater cleanup by graphene composite paper for tailorable supercapacitors. ACS Appl Mater Interfaces 9:21298-21306

13. Yang J, Wang H, Yang Y, Wu J, Hu P, Guo L (2017) Pseudocapacitive-dyemolecule-based high-performance flexible supercapacitors. Nanoscale 9:9879-9885

14. Xu C, Wang H, Deng J, Wang Y (2018) High-performance flexible redox supercapacitors induced by methylene blue with a wide voltage window. Sustain Energy Fuels 2:357-360

15. Liu J, Mu S (1999) The electrochemical polymerization of methylene blue and properties of polymethylene blue. Synth Met 107:159-165

16. Kertesz V, Van Berkel GJ (2001) Electropolymerization of methylene blue investigated using on-line electrochemistry/electrospray mass spectrometry. Electroanalysis 13:1425-1430

17. Ortega PF, de Paula FG, de Castro MC, Binatti I, González Z, Blanco C, Lavall RL (2018) Mechanism and stability of a redox supercapacitor based on methylene blue: effects of degradation of the redox shuttle. ACS Appl Energy Mater 1:2306-2316

18. Pandit B, Dubal DP, Sankapal BR (2017) Large scale flexible solid state symmetric supercapacitor through inexpensive solution processed $\mathrm{V}_{2} \mathrm{O}_{5}$ complex surface architecture. Electrochim Acta 242:382-389

19. Senthilkumar K, Prabakar SJR, Park C, Jeong S, Lah MS, Pyo M (2016) Graphene oxide self-assembled with a cationic fullerene for high performance pseudocapacitors. J Mater Chem A 4:1663-1670

20. Akinwolemiwa B, Peng C, Chen GZ (2015) Redox electrolytes in supercapacitors. J Electrochem Soc 162:A5054-A5059

21. Samyn LM, Babu RS, Devendiran M, de Barros ALF (2020) Electropolymerization of $\mathrm{p}$-phenylenediamine films on carbon fiber fabrics electrode for flexible supercapacitors: surface and electrochemical characterizations. Ionics 26:3041-3050

22. Schlereth DD, Karyakin AA (1995) Electropolymerization of phenothiazine, phenoxazine and phenazine derivatives: characterization of the polymers by UV-visible difference spectroelectrochemistry and Fourier transform IR spectroscopy. J Electroanal Chem 395:221-232

23. Barsan MM, Pinto EM, Brett CMA (2008) Electrosynthesis and electrochemical characterisation of phenazine polymers for application in biosensors. Electrochim Acta 53:3973-3982

\section{Publisher's Note}

Springer Nature remains neutral with regard to jurisdictional claims in published maps and institutional affiliations. 